\title{
Characterization of Tapioca Residue and Coir Fiber as Reinforcement Foam Composites Obtained by Compression Molding
}

\author{
Tarinee Nampitch ${ }^{1,}$, Thiti Kaisone ${ }^{1, b^{*}}$, Pran Hanthanon ${ }^{1, c}$, Chanon Wiphanurat ${ }^{1, d}$, \\ Sumate Ouipanich $^{1, \mathrm{e}}$ and Yupawan Thongjun ${ }^{1, \mathrm{f}}$ \\ ${ }^{1}$ Department of Packaging and Materials Technology, Faculty of Agro-Industry, \\ Kasetsart University, Bangkok, Thailand
}

\begin{abstract}
The global waste problem is a worldwide problem, which is a factor of global warming. Biopolymers are one of the factors that can lead to solving the problem. The tapioca starch/coirfiber foam composites in which all materials were natural and eco-friendly were studied for this research paper. For the purpose of this study, the tapioca starch was a waste product from the tapioca industry and coirfiber was used as a reinforcing agent. $\mathrm{NaHCO}_{3}$ was used as a foaming agent, and the coirfiber was modified by conducting an alkaline process before mixing it with the tapioca starch. The Fourier transform infrared spectroscopy (FTIR) was used to analyze the characteristics of the tapioca starch and modified coirfiber. The melt flow index (MFI) analyzed the physical properties of the tapioca starch/coirfiber foam composites. The morphology of the tapioca starch/coirfiber foam composites were tested by scanning electron microscopy and the mechanical properties of the tapioca starch/coirfiber foam composites were tested by a tensile test.
\end{abstract}

Keywords: Tapioca waste, Coir fibre, Foam composites, Thermoplastic starch, Biopolymers

\section{Introduction}

Pollution is one of the major concerns in every country in the world. Also, plastic waste is one of the problems in each nation. Most of the plastics used are non-biodegradable polymers, which are made from petroleum-based materials. Non-biodegradable polymers are not environmentally-friendly and can harm the natural environment [1]. Biodegradable plastics or biopolymers and waste residue from agricultural products can solve the plastic waste problems from the degradability of the materials. This is due to the commercial biopolymers, which are widely known as polylactic acid (PLA), poly butyl succinate (PBS), Thermoplastic starch (TPS), etc. [2]

Biopolymers are one of the most interesting materials in every industry because of the degradability and eco-friendly properties of the materials. The biopolymers are made from agricultural products or waste from the farms or industries; such as, corn, sugar cane, etc. [3]. Biopolymers have more disadvantages than nonbiodegradable polymers even though the biopolymers are harmless to the environment. They have a higher cost and lower properties than non-biodegradable polymers, so biopolymers cannot be widely used in many industries [4].

Thermoplastic starch (TPS) is one of the most important biodegradable polymers that needs to have more research conducted to improve the properties of the materials. TPS is made from agricultural products and waste products from various industries [5,6]. The advantage of TPS is the non-toxicity, degradability, inexpensiveness and ease to find in every country because all the agricultural products can be derived to be TPS [7]. Most of the research and work has obtained the TPS by using a casting method, but the major concern of using TPS is the water resistance and low mechanical properties than the non-biodegradable polymers. However, the problem of 
water resistance can be solved by adding additive or plasticizer when TPS needs to be used as a blended polymer with other polymers to improve the properties and lower the cost of the blended polymer $[8,9]$.

The natural fiber has been used as a reinforcing agent in the composite process to improve the properties of the polymer composites due to the low cost, eco-friendliness and ease to find [10]. To improve the homogenous and adhesion of the polymers and natural fiber phase, many studies modified the natural fiber to remove the lignin and hemi-cellulose of the natural fiber, which can interfere with the adhesion between the two phases of the composite. There are many natural fibers widely used; such as, coconut, jute, flax, hemp, etc. [11,12]

The objective of this study was to focus on developing the tapioca residue from the industries' waste to become thermoplastic starch, study the effects of the amount of the coir fiber and the effects of the foaming agent on the mechanical properties and morphology of the TPS/coir fiber foam composite. The coir fiber was modified by conducting an alkaline treatment process and grinding the coir fiber by using a pulverizer machine.

\section{Materials and Methods}

\subsection{Materials}

Natural foam composite was prepared from tapioca residue as a base were supplied by RT AGRITE., LTD. With the plasticizer of glycerol employed in this research work is $30 \% \mathrm{w} / \mathrm{w}$ supplied by Quality Reagent Chemical. Coir fiber used for reinforcement was provided by Victory Industrial Company Limited

\subsection{Preparation of Natural Foam Composite}

TABLE I: The Composition of Natural foam composite

\begin{tabular}{cccc}
\hline \hline Sample name & Tapioca residue $(\%)$ & Coirfiber $(\%)$ & Glycerol $(\%)$ \\
\hline TPS/C5 & 95 & 5 & 30 \\
TPS/C10 & 90 & 10 & 30 \\
TPS/C20 & 80 & 20 & 30 \\
\hline \hline
\end{tabular}

Impurities and contaminants were removed from the tapioca residues, followed by drying at $60^{\circ} \mathrm{C}$ for 12 hours in an oven to remove all moisture before grinding into a powder. A twin screw extruder was used to blend tapioca residues, coir fiber and plasticizer at various ratios as shown in Table1. Temperature profiles were set from feed zone to die at 110,110 , and $120^{\circ} \mathrm{C}$ with screw speed maintained at $60 \mathrm{rpm}$. The extruder obtained from the die was cooled in the atmosphere and cut into pellets. The Natural foam composite were compressed at $170^{\circ} \mathrm{C}$ for 9 minutes using a compression molding machine and cooling for 9 minutes.

\subsection{Fourier Transform Infrared (FT-IR) Spectroscopy}

Fourier transform infrared (FT-IR) spectroscopy was used in order to detect the presence of the functional group existed in tapioca residue. The range of wavenumber was attributed from 4000 to $400 \mathrm{~cm}^{-}$ ${ }^{1}$ in ATR )Attenuated Total Reflectance( mode with Resolution $2 \mathrm{~cm}^{-1}$

\subsection{Mechanical Properties}

Tensile testing results determined tensile strength, elongation at break and modulus according to ASTM D638. Tensile testing was performed at $23^{\circ} \mathrm{C}$ using an Instron machine with crosshead speed of $1 \mathrm{~mm} / \mathrm{min}$ on at least five dumbbell-shaped specimens of each material type $\mathrm{V}$.

\subsection{Melt Flow Index (MFI)}

Natural foam composites were examined by using DYNISCO MFI machine at 170。C with load cell $10 \mathrm{Kg}$. For measuring of the ease of flow of the melt of foams. 


\section{6. canning Electron Microscopy (SEM)}

Natural foam composite were examined by using scanning electron microscope operated at $15 \mathrm{kV}$. The specimens were fractured under cryogenic condition in liquid nitrogen and the fractured surfaces vacuum were coated with paradium for scanning electron microscope.

\section{Result and Discussion}

\subsection{Fourier Transform Infrared (FT-IR) Spectroscopy}

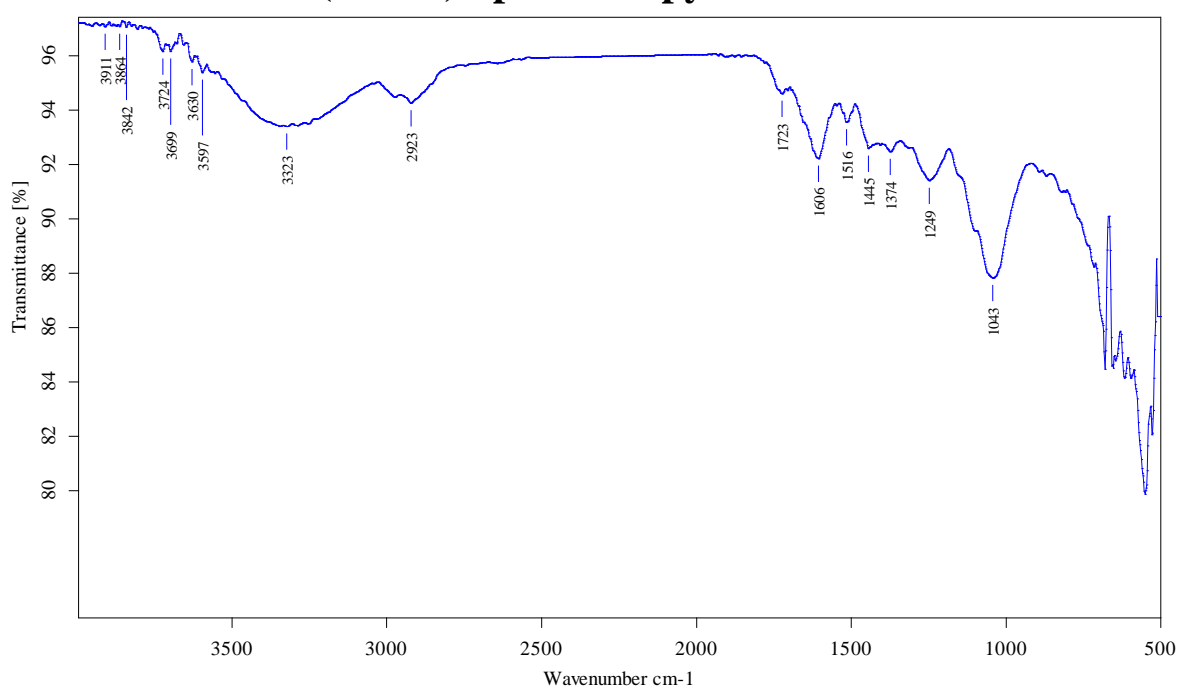

Fig 1. FT-IR spectra of coir fiber

The FTIR spectroscopy indicates the chemical composition as shown in Fig.1. The peak range of 1300-2000 cm-1 for the coir fiber could be presented in $1328 \mathrm{~cm}^{-1}, 1408 \mathrm{~cm}^{-1}, 1447 \mathrm{~cm}^{-1}, 1509 \mathrm{~cm}^{-1}, 1673 \mathrm{~cm}^{-1}$ and 2923 $\mathrm{cm}^{-1}$ of $-\mathrm{CH}_{2}$ of the cellulose, $-\mathrm{CH}$ bending alkane methyl group, $-\mathrm{CH}$ deformation in aliphatic, $\mathrm{C}=\mathrm{C}$ of lignin's aromatic, hydroxyl of cellulose and $-\mathrm{CH}$ stretching alkane, respectively. In addition, the peak at $1745 \mathrm{~cm}^{-1}$ attributed to the conjugated carbonyl group of hemicellulose. [13]

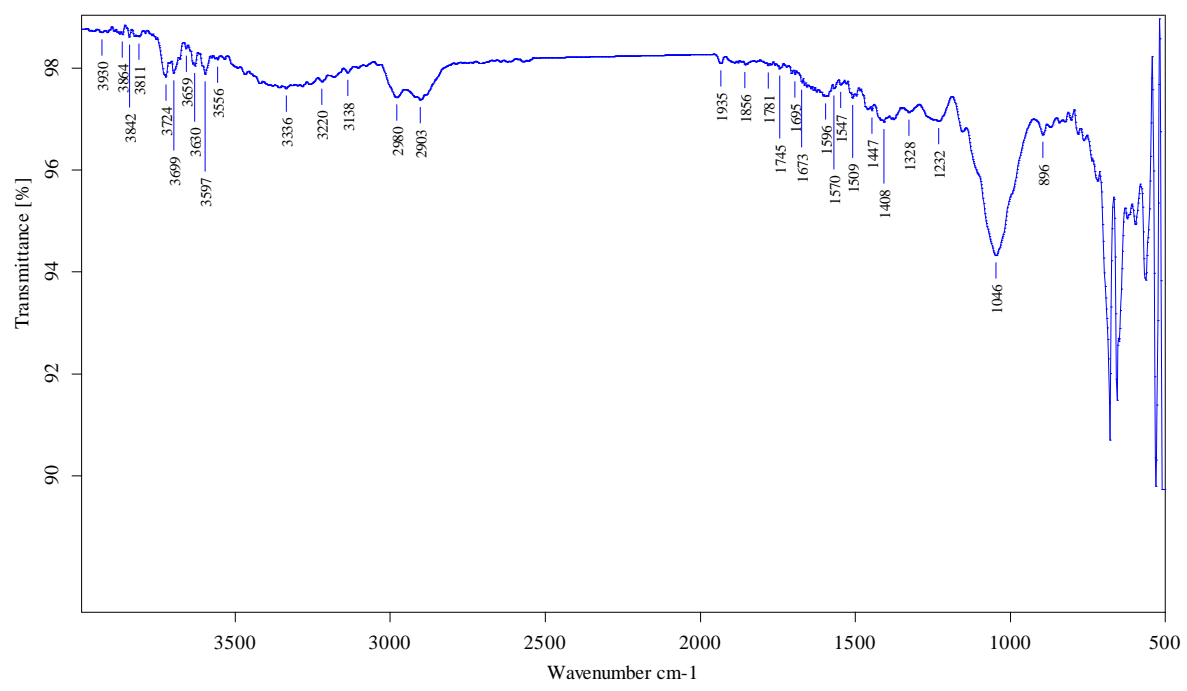

Fig 2. FT-IR spectra of modifier coir fiber

Furthermore, the treated coir fiber at a peak of $1046 \mathrm{~cm}-1$ could be shown in the hydroxyl group of fibers more deeply than the coir fiber indicating that $\mathrm{NaOH}$ could leach the lignin composition, but appearing as the 
cellulose in the stand. In addition, the peak of $896 \mathrm{~cm}-1$ attributed to the glycosidic bond, which expected it to be completely destroyed. [13]

\subsection{Mechanical Properties}

TABLE II: Mechanical Properties of the Tapioca Starch/Modified Coir Fiber Foam Composites

\begin{tabular}{ccccc}
\hline \hline Sample name & Tensile strength $(\mathrm{MPa})$ & Elongation at break $(\%)$ & Modulus(MPa) & Melt flow index (g/10 min) \\
\hline TPS/C5 & 8.42 & 3.96 & 613.13 & 1.1 \\
TPS/C10 & 9.95 & 3.46 & 614.36 & 3.46 \\
TPS/C20 & 11.82 & 3.29 & 766 & 0.2 \\
\hline \hline
\end{tabular}

Table 2 shows the result of the mechanical properties of the tapioca starch/modified coir fiber foam composites, which contained 1, 10 and 20 percent w/w, respectively of the modified coir fiber. The result showed the increasing in the modified coir fiber had increased the mechanical properties of the composite samples because the coir fiber was modified by using an alkaline process [14]. This could improve the interfacial bond or adhesion between the tapioca residue and modified coir fiber by removing the lignin, hemicellulose and other compositions from the coir fiber and a reduced amount of modified coir fiber had improved the dispersion of the coir fiber in the matrix phase of the foam composites. [15, 16]

\subsection{Melt Flow Index (MFI)}

From data shown in Table 2, the result of the melt index flow index data of the tapioca starch/modified coir fiber foam composites contained 5, 10 and 20 percent w/w of the modified coir fiber, respectively. The data of the melt flow index were $1.10,3.46$ and $0.20 \mathrm{~g} / 10 \mathrm{~min}$, respectively. The rise in the natural fiber had increased the MFI data until the amount of natural fiber was optimized. The increasing of the natural fiber had interrupted the polymer chain orientation, so the glass transition temperature $(\mathrm{Tg})$ had decreased by the natural fiber. The decreasing of the MFI data occurred because the amount of natural fiber was too high, and the natural fiber was burned and blocked the melt flow chamber instrument. [17]

\subsection{Scanning Electron Microscopy (SEM)}

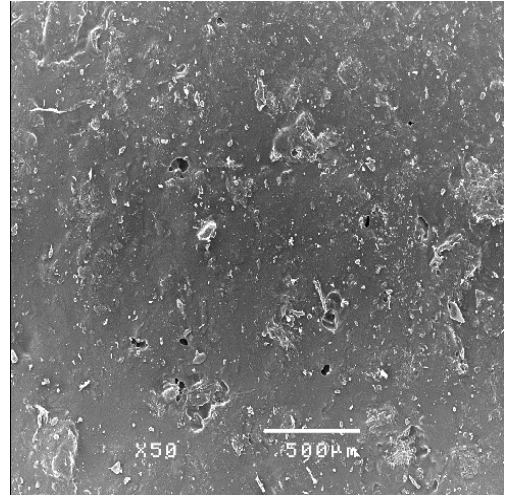

(a)

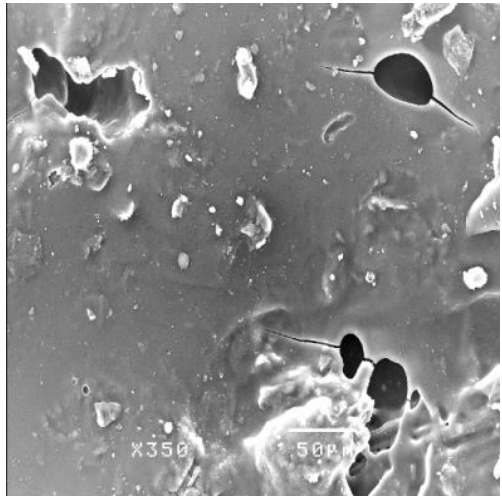

(b)

Fig 3 SEM image of tapioca starch $/ 5 \%$ coir fiber $2 \% \mathrm{NaHCO}_{3}$ foam composites (a) $\times 50$ (b) $\times 350$ 


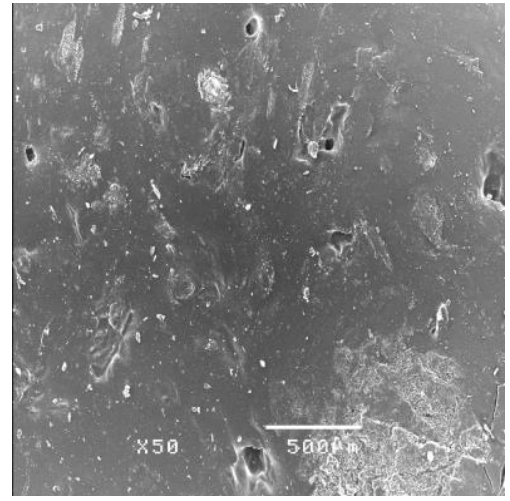

(a)

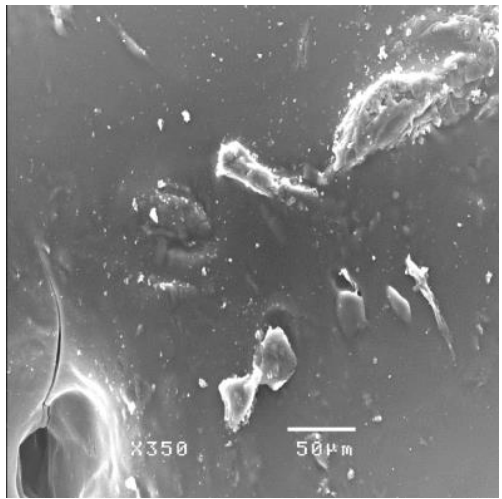

(b)

Fig 4 SEM image of tapioca starch $/ 10 \%$ coir fiber $2 \% \mathrm{NaHCO}_{3}$ foam composites (a) $\times 50$ (b) $\times 350$

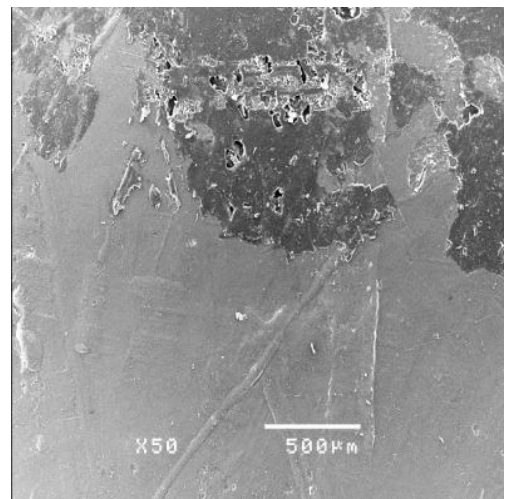

(a)

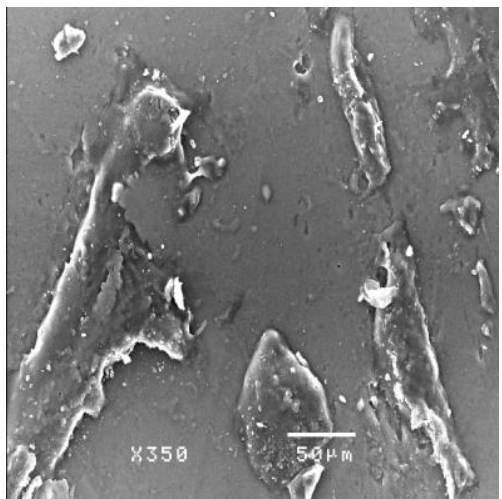

(b)

Fig 5 SEM image of tapioca starch $/ 20 \%$ coir fiber $2 \% \mathrm{NaHCO}_{3}$ foam composites (a) $\times 50$ (b) $\times 350$

Fig. 3 shows the SEM images of the tapioca residue foam composites with 2 percent of $\mathrm{NaHCO}_{3}$. Fig. 3 (a) and (b) show the brittleness and porousness of the foam cell on the surface of the tapioca residue foam composite. Fig. 2 shows the SEM images of the tapioca residue/modifier coir fiber foam composites with 2 percent of $\mathrm{NaHCO}_{3}$. Fig. 3 (a) and (b) show the morphology of the tapioca residue foam composite reinforced with 5 percent of the modifier coir fiber. The surface area shows good adhesion and good homogeneity between the tapioca residue and coir fiber because the tapioca residue consisted of cellulose, which had the same chemical structure with modified coir fiber [18]. The coir fiber showed good dispersion and discontinued the direction of the coir fiber in the tapioca residing matrix. The coir fiber was modified by conducting an alkaline process before mixing it with the tapioca residue. The alkaline process could improve the interfacial bond and adhesion between the tapioca residue and modified coir fiber by removing the lignin, hemicellulose and other compositions from the coir fiber. Fig. 4 (a) and (b) show the morphology of the tapioca residue foam composite reinforced with 10 percent of the modified coir fiber. The surface area also shows good adhesion and good homogeneity between the tapioca starch and coir fiber the same as fig. 3. Fig. 4b shows the SEM image at 350 times magnification of the sample. The image clearly showed the surface of the modified coir fiber, which was smooth and clean after the modification process and had good homogeneity with the tapioca residue. Fig. 5 (a) and (b) show the morphology of the tapioca residue foam composite reinforced with 20 percent of the modified coir fiber. This also showed the same result as fig. 3 and 4 in which the surface area of the sample showed good adhesion and good homogeneity between the tapioca starch and coir fiber. Fig. 3, 4 and 5 showed the foam porous cell on the surface of the foam composite. The increasing of the coir fiber had decreased the foamability, foam stability and low foam porous dispersion in the composite because the increase of the coir fiber had interrupted and prevented the foam porous cell in the composite.[19] 


\section{Conclusion}

The properties of the natural foam composites showed significant change after increasing the amount of coir fiber and the modified coir fiber that was modified by conducting an alkaline process, which had improved the mechanical properties. The surface area of the coir fiber after the alkaline process was smoother and cleaner. The study showed that the alkaline process had improved the interfacial bond and adhesion between the tapioca residue and modified coir fiber by removing the lignin, hemicellulose and other compositions from the coir fiber. The interfacial bond between the tapioca residue and modified coir fiber was the factor, which improved the mechanical properties of the natural foam composite and also the amount of the modified coir fiber that increased the mechanical properties of the natural foam composite.

\section{Acknowledgement}

This research was financially supported by the Thailand research fund.

\section{Reference}

[1] O. Lopez, M.A. Garcia, M.A. Villar, A. Gentili, M.S. Rodriguez and L. Albertengo, "Thermo-compression of biodegradable thermoplastic corn starch films containing chitin and chitosan," LWT-FOOD SCI TECHNOL, Vol. 57, pp. 106-115, June 2014.

https://doi.org/10.1016/j.lwt.2014.01.024

[2] J. Prakash Maran, V. Sivakumara, R. Sridhar and V. Prince Immanuel, "Development of model for mechanical properties of tapioca starch based edible films," IND CROP PROD, Vol. 42, pp. 159-168, March 2013.

https://doi.org/10.1016/j.indcrop.2012.05.011

[3] J.M. Ferri, D. Garcia-Garcia, L. Sánchez-Nacher, O. Fenollar and R. Balart, "The effect of maleinized linseed oil (MLO) on mechanical performance of poly (lactic acid)-thermoplastic starch (PLA-TPS) blends," CARBOHYD POLYM, Vol.147, pp. 60-68, August 2016.

https://doi.org/10.1016/j.carbpol.2016.03.082

[4] J. Prakash Maran, V. Sivakumarb, R. Sridhar and K. Thirugnanasambandham, "Development of model for barrier and optical properties of tapioca starch based edible films," CARBOHYD POLYM, Vol. 92, pp. 1335- 1347, February 2013.

https://doi.org/10.1016/j.carbpol.2012.09.069

[5] Khanh Minh Dang and Rangrong Yoksan, "Morphological characteristics and barrier properties of thermoplastic starch/chitosan blown film," CARBOHYD POLYM, Vol. 150, pp. 40-47, October 2016.

https://doi.org/10.1016/j.carbpol.2016.04.113

[6] A. Ostafińska, J. Mikešová, S. Krejč́́ková, M. Nevoralová, A. Šturcová, A. Zhigunov, D. Michálková, and M. Šlouf, "Thermoplastic starch composites with $\mathrm{TiO}_{2}$ particles: Preparation, morphology, rheology and mechanical properties," INT J BIOL MACROMOL, Vol. 101, pp. 273-282, August 2017.

https://doi.org/10.1016/j.ijbiomac.2017.03.104

[7] Nikhil Biswas and Ranjan Kumar Sahoo, "Tapioca starch blended alginate mucoadhesive-floating beads for intragastric delivery of Metoprolol Tartrate,” INT J BIOL MACROMOL, Vol. 83, pp. 61-70, February 2016.

https://doi.org/10.1016/j.ijbiomac.2015.11.039

[8] S. Kampangkaew, C. Thongpin and O. Santawtee, "The synthesis of Cellulose nanofibers from sesbania javanica for filler in thermoplastic starch,” ENRGY PROCED, Vol. 56, pp. 318 - 325, 2014

https://doi.org/10.1016/j.egypro.2014.07.163 
[9] N. Azmi, A. A. Bakar, S. A. Samsudin and N. A. A. Aziz, "Preparation and characterization of tapioca starch filled polycaprolactone composition films," MJAS, Vol. 18, pp. 612 - 617, 2014.

[10] T. H. Nam, S. Ogihara and S. Kobayashi,'Interfacial, mechanical and thermal properties of coir fiber-reinforced poly (lactic acid) biodegradable composites," ADV COMPOS MATER, Vol. 21, pp. 103-122, July 2012.

https://doi.org/10.1080/09243046.2012.723362

[11] J. Y. Jang, T. K. Jeong, H. J. Oh, J. R. Youn and Y. S. Song, "Thermal stability and flammability of coirfiber reinforced poly (lactic acid) composites," Composites: Part B, Vol. 43, pp. 2434-2438, July 2012.

https://doi.org/10.1016/j.compositesb.2011.11.003

[12] A. P. Mathew, K. Oksman and M. Sain, "Mechanical properties of biodegradable composites from poly lactic acid (PLA) and microcrystalline cellulose (MCC)," J APPL POLYM SCI, Vol. 97 pp. 2014-2025, June 2005.

https://doi.org/10.1002/app.21779

[13] K. O. Reddy, M. Shukla, C. U. Maheswari, and A. V. Rajulu, "Mechanical and physical characterization of sodium hydroxide treated Borassus fruit fibers," JFR, Vol. 23, pp. 667-674, April 2011.

[14] M. F. Rosa, B. Chiou, E. S. Medeiros, D. F. Wood, T.G. Williams, L. H.C. Mattoso, W.J. Orts and S. H. Imam,” Effect of fiber treatments on tensile and thermal properties of starch/ethylenevinyl alcohol copolymers/coir biocomposites," BIORESOURCE TECHNOL, Vol. 100, pp. 5196-5202, June 2009.

https://doi.org/10.1016/j.biortech.2009.03.085

[15] J. G. G. Farias, R. C. Cavalcante, B. R. Canabarro, H. M. Viana, S. Scholz and R. A. Simão, "Surface lignin removal on coir fibers by plasma treatment for improved adhesion in thermoplastic starch composites," CARBOHYD POLYM, Vol. 165, pp. 429-436, February 2017.

https://doi.org/10.1016/j.carbpol.2017.02.042

[16] P. Surin, P. Rakkwamsuk, E. Wimolmala and N. Sombatsompop, "Effects of coir fiber and maleic anhydride modification on the properties of thermoplastic starch/PLA composite laminates," J NAT FIBERS, Vol. 12, pp. 180120, November 2014.

[17] A. V'quez and V. Alvarez, Biodegradable Polymer Blends and Composites from Renewable Resources, 1st ed. New jersey, USA: Wiley, 2008, ch.11, pp. 270-272.

[18] M. G. L. Ramirez, K. G. Satyanarayana, S. Iwakiri, G. B. Muniz, V. Tanobe and T. S. Flores-Sahagun, "Study of the properties of biocomposites. Part I. Cassava starch-green coir fibers from Brazil," CARBOHYD POLYM, Vol. 86, pp. 1712-1722, July 2011.

https://doi.org/10.1016/j.carbpol.2011.07.002

[19] D. Verma, P.C. Gope, A. Shandilya, A. Gupta and M.K. Maheshwari, "Coir fibre reinforcement and application in polymer composites: a Review," J MATER ENVIRON SCI, Vol. 4, pp. 263-276, October 2012.

[20] T. Kaisone, N. Harnkarnsujarit, T. Leejarkpai, and T. Nampitch, "Mechanical and thermal properties of toughened PLA composite foams with modified coirfiber,” AMM, vol. 851, pp. 179-185, June 2016.

https://doi.org/10.4028/www.scientific.net/AMM.851.179 